\section{Commentary: Introducing positive discrimination}

\author{
Christian P. Brizard, MD
}

The surgeons who have preceded us and taught us knew from instinct and experience that one must discriminate in balancing the circulations through systemic to pulmonary shunts (single ventricles with common atrioventricular valves can tolerate 1 shunt but not 2 shunts). Failing to retain this teaching has led to a seemingly Gordian knot when we need to decide whether to preserve (or add) antegrade pulmonary blood flow to the bidirectional cavopulmonary connection at the time of the intermediate stage toward the Fontan circulation.

In their retrospective analysis published in the Journal, Baek and colleagues ${ }^{1}$ report that right ventricular dominance, common atrioventricular valve morphology, the presence of right atrial isomerism, ventricular dysfunction, or severe atrioventricular valve regurgitation were evenly distributed between groups that received and did not receive additional pulmonary blood flow. These anatomic and functional subgroups are precisely the groups of patients most sensitive to volume loading. Consistent with other available literature on this topic, the authors demonstrate a favorable effect of additional pulmonary blood flow on oxygen saturation and pulmonary artery growth. In Melbourne, we have also found a positive effect on exercise ability during the interstage period.

Unsurprisingly, the authors report a negative effect on the freedom from death or transplantation, especially during the interstage period, when additional pulmonary blood flow is applied.

Had the authors wished to design a prospective study to demonstrate the negative effects of the additional volume

\footnotetext{
From the Department of Cardiac Surgery, The Royal Children's Hospital, Murdoch Children's Research Institute, and Department of Paediatrics, University of Melbourne, Melbourne, Australia.

Disclosures: The author reported no conflicts of interest.

The Journal policy requires editors and reviewers to disclose conflicts of interest and to decline handling or reviewing manuscripts for which they may have a conflict of interest. The editors and reviewers of this article have no conflicts of interest.

Received for publication Feb 8, 2021; revisions received Feb 8, 2021; accepted for publication Feb 8, 2021; available ahead of print Feb 16, 2021.

Address for reprints: Christian P. Brizard, MD, Department of Cardiac Surgery, The Royal Children's Hospital Melbourne, 50 Flemington Rd, Parkville, 3052 Victoria, Australia (E-mail: christian.brizard@rch.org.au).

J Thorac Cardiovasc Surg 2021;162:1358-9

$0022-5223 / \$ 36.00$

Copyright (c) 2021 by The American Association for Thoracic Surgery

https://doi.org/10.1016/j.jtcvs.2021.02.027
}

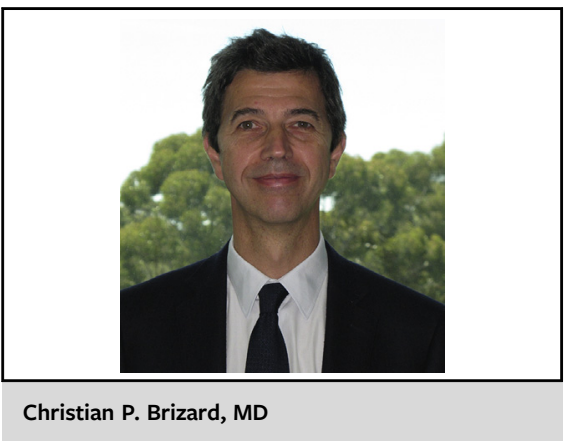

CENTRAL MESSAGE

The debate on antegrade pulmonary blood flow during bidirectional cavopulmonary shunts could be made simpler if ventricular dominance, atrioventricular valve anatomy, and ventricular function were part of the decision making algorithm.

loading on patients with the above anatomy or function, they would have used their present cohorts.

In Melbourne, we have demonstrated the benefits of reducing the volume loading in patients with right ventricular dominance with the bidirectional cavopulmonary connection, ${ }^{2}$ and we do this at 3 months of age. ${ }^{3}$ In addition, we have described the detrimental role of the common atrioventricular valve anatomy and its propensity to evolve toward moderate or severe regurgitation, even when the Fontan operation is completed. ${ }^{4}$ This has led to the pursuit of a policy in which patients are divided into 2 categories. The first category is those able to sustain volume loading, without additional risk of failure, who would benefit from controlled additional pulmonary blood flow during the interstage period. These are patients with left ventricular dominance, good function, without common atrioventricular valveor greater than mild atrioventricular valve regurgitation. Patients with all other anatomies, particularly right ventricular dominance and common atrioventricular valve, should not receive any source of supplementary pulmonary blood flow. Following this strategy, we were able to demonstrate the benefits of additional pulmonary blood flow during interstage and their extension beyond Fontan completion. 


\section{References}

1. Baek JS, Park CS, Choi ES, Yun TJ, Kwon BS, Yu JJ, et al. The impact of additional antegrade pulmonary blood flow at bidirectional Glenn shunt on long-term outcomes. J Thorac Cardiovasc Surg. 2021; 162:1346-55.e4

2. d'Udekem Y, Xu MY, Galati JC, Lu S, Iyengar AJ, Konstantinov IE, et al. Predictors of survival after single-ventricle palliation the impact of right ventricular dominance. J Am Coll Cardiol. 2012;59:1178-85.
3. Kelly TJ, Zannino D, Brink J, Konstantinov IE, Cheung MM, d'Udekem Y, et al. A shunt decision-making protocol in the surgical palliation of hypoplastic left heart syndrome from 2004 to 2016. Eur J Cardiothorac Surg. 2020;58:153-62.

4. King G, Ayer J, Celermajer D, Zentner D, Justo R, Disney P, et al. Atrioventricular valve failure in Fontan palliation. J Am Coll Cardiol. 2019;73:810-22.

5. Sughimoto K, Zannino D, Mathew J, Weintraub RG, Brizard CP, d'Udekem Y, et al. Forward flow through the pulmonary valve after bidirectional cavopulmonary shunt benefits patients at Fontan operation. Ann Thorac Surg. 2015;100:1390-7.
See Article page 1346.

\section{Commentary: One size fits some- additional pulmonary blood flow at the Glenn operation and patient-specific factors}

\author{
Neel K. Prabhu, BSE, ${ }^{a}$ Nicholas D. Andersen, MD, ${ }^{\mathrm{a}, \mathrm{b}, \mathrm{c}}$ \\ and Joseph W. Turek, MD, PhD, MBA ${ }^{\mathrm{a}, \mathrm{b}, \mathrm{c}}$
}

Preservation of additional pulmonary blood flow (APBF) at the Glenn operation is a controversial topic that has been discussed in the literature since the mid-1990s. ${ }^{1}$ In this issue of the Journal, Baek and colleagues ${ }^{2}$ perform a long-term, retrospective analysis of a cohort of more than 200 singleventricle patients to further investigate. The authors found that the group of patients who received the Glenn operation with preservation of APBF had more than 2-fold greater risk of death or transplant (hazard ratio, 2.37) as well as a 3-fold greater probability of prolonged chest tube drainage and readmission (odds ratio, 3.204) after Glenn—a striking result.

Overall, the authors should be commended for their work. Few publications on outcomes after the Glenn operation have a study period (15 years), follow-up length

\footnotetext{
From the ${ }^{\mathrm{a}}$ Duke Congenital Heart Surgery Research \& Training Laboratory, and ${ }^{\mathrm{b}} \mathrm{Di}$ vision of Thoracic and Cardiovascular Surgery, Duke University, Durham, NC; and 'Duke Children's Pediatric \& Congenital Heart Center, Duke Children's Hospital, Durham, NC.

Disclosures: The authors reported no conflicts of interest.

The Journal policy requires editors and reviewers to disclose conflicts of interest and to decline handling or reviewing manuscripts for which they may have a conflict of interest. The editors and reviewers of this article have no conflicts of interest.

Received for publication Jan 20, 2021; revisions received Jan 20, 2021; accepted for publication Jan 21, 2021; available ahead of print Jan 30, 2020.

Address for reprints: Joseph W. Turek, MD, PhD, MBA, Division of Thoracic and Cardiovascular Surgery, Duke University Medical Center, 2301 Erwin Rd, DUMC 3443, Durham, NC 27710 (E-mail: joseph.turek@ duke.edu).

J Thorac Cardiovasc Surg 2021;162:1359-60

$0022-5223 / \$ 36.00$

Copyright (c) 2021 by The American Association for Thoracic Surgery

https://doi.org/10.1016/j.jtcvs.2021.01.082
}

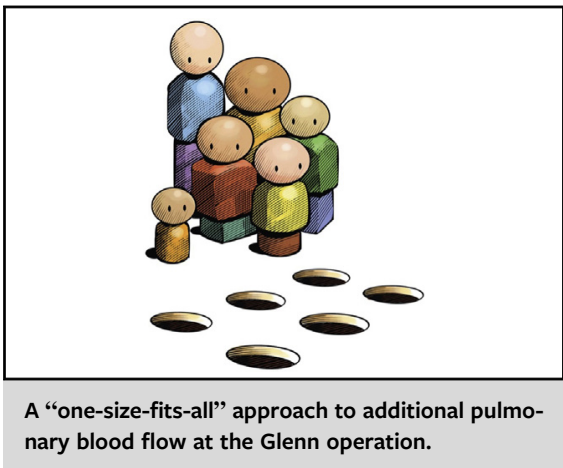

CENTRAL MESSAGE

Outcomes after the Glenn operation may improve by identifying quantitative criteria that define an individual patient's chance of survival if additional pulmonary blood flow is preserved or not.

(mean 8.4 years after Fontan), cohort size (more than 200 patients), and distribution of cardiac diagnoses as robust as the study here. In addition, the use of propensity matching is thoughtful, as it controls for the presence of ventricular dysfunction, oxygen saturation, atrioventricular valve morphology, and other preoperative variables. However, the study is not without its limitations. For one, despite propensity matching, there is a high likelihood of selection bias with patients presenting at Glenn with smaller pulmonary arteries (PAs) more likely to be in the APBF group. This confounds the analysis, since the propensity score did not incorporate the key variable of pre-Glenn PA size. Furthermore, the supplementary data suggest that patients who 